\title{
Medically necessary: Who should decide?
}

A decision as to whether something is or isn't necessary depends a whole lot on who's doing the deciding. A new opera house downtown? "Yes," says the music-loving arts community. "No," says the cashstrapped city council. A new 90 -inch television? "Yes," says the sports-mad husband. "No," says the level-headed wife.

In health care, opinions about whether a particular service, test or procedure is "medically necessary" - and therefore covered by provincial health plans - can also vary widely. Equally divisive, in some quarters, are opinions about who should be involved in making that decision.

"Medical necessity should be determined between the patient and the health care provider," says Dr. Douglas Mark, president of the Coalition of Family Physicians and Specialists of Ontario. "It should not be the government making that decision."

According to Mark, the Ontario government is about to start "micromanaging" health care in the province. The government will now decide if certain services, such as providing an MRI (magnetic resonance imaging) for low back pain, are really necessary and worthy of reimbursement through public funds. Mark claims this could eventually affect many fields of medicine, including cardiology, neurology, anesthesiology and ophthalmology.

"Some nameless, faceless bureaucrat in the government will decide who is or is not eligible for coverage for these X-rays, CT [computed tomography], and MRI scans. Another example is mammograms," Mark stated in a press release (www.cofps.ca/2012/05 131/ontario-is-now-micromanaging-your -health-care). "Ultimately, it will be our patients who will have to pay for these tests themselves with their health or even their lives, despite having already paid for health care through taxes and the additional healthcare levy."

In response to government plans to revise the process for determining

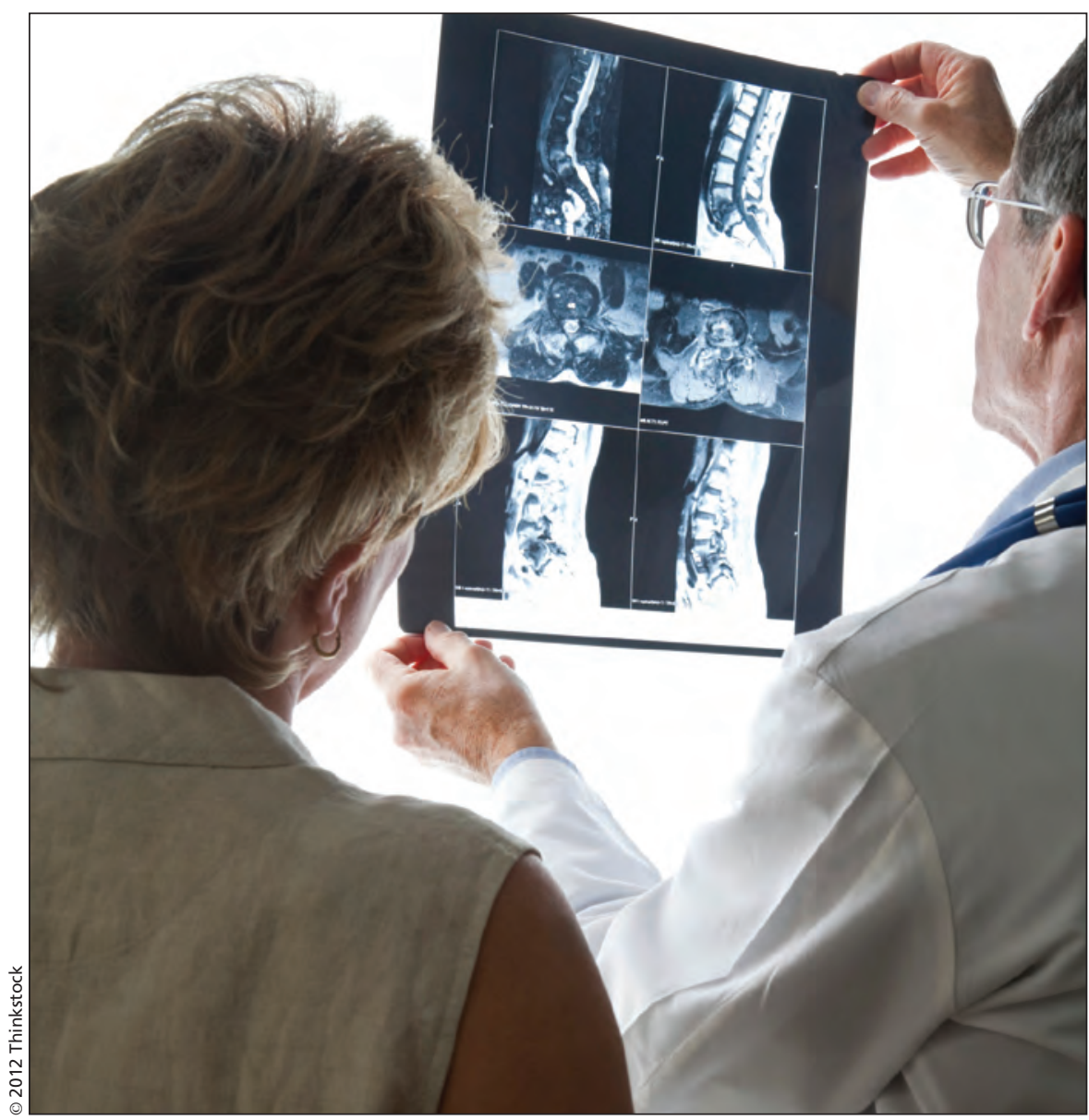

Ontario doctors will no longer be reimbursed for magnetic resonance imaging scans for patients with low back pain if the government deems them unnecessary.

what's medically necessary, the coalition has issued a "call to arms" asking doctors to send an "Ontario Medically Necessary Authorisation Requestion Form" to the province (www.cofps.ca /wp-content/uploads/2012/05/Medically -Necessary-Authorisation-Requisition -Form1.pdf). It states that a patient is "waiting in office/clinic/hospital for your immediate reply" regarding his eligibility for at least one of a number of tests, including electrocardiogram, mammogram, ocular ultrasound, cataract surgery sedation, x-ray of the lumbar spine and electroencephalogram.

"It's ludicrous. They're the ones now making decisions, from the top down," says Mark. "It's completely backwards."

The government takes issue with that proposition. The point of the increased scrutiny is not to undermine physicians, but rather to base spending decisions on evidence instead of the judgment of physicians alone, says Deb Matthews, Ontario's Minister of Health and Long-Term Care.

The government will rely on expert committees - comprising physicians, academics and other experts - to review scientific literature and determine when, and for whom, a test or procedure is actually necessary. "We want people to get the care they need, but we don't want people to go through unnecessary tests and we don't want to pay for it," says Matthews. "I really believe doctors want to do what's right for patients and for the system, and some might interpret this as 
a challenge to their autonomy, but we have to do what's right for patients and what's right for the health care system."

Evidence suggests, for instance, that physicians are far more likely to order a test if they own the machine needed to perform it, notes Matthews. There is also a tendency among some doctors to order expensive tests prematurely. "We do know that some physicians were sending people with lower back pain for MRIs before doing anything else," says Matthews.

Academics who have studied processes for determining what is medically necessary tend to agree that clinicians shouldn't be the only ones involved. Though medical expertise is of course required, the reality is that money comes into play as well. Every public dollar spent on health care, after all, is a dollar that can't be spent to provide other types of services to citizens. And nobody expects doctors to make decisions about patient care based on how it will affect, say, teachers' salaries.

"There really is a role for people other than doctors in the process," says Mark Stabile, director of the School of Public Policy and Governance and professor of economics and public policy at the Rotman School of Management of the University of Toronto in Ontario.
Efforts to contain costs don't necessarily detract from the quality of health care, Stabile says. In fact, more efficient care can sometimes be better care, even if physicians are reluctant to accept outside influence on how their practices should be run.

"Everybody would prefer to have nobody interfere with them, but there is some evidence, a lot of it from the United States, that when doctors are shown they can do a job better by making some adjustments, in the long run they are happier," says Stabile.

According to some observers, bringing a wider range of experts into the mix is long overdue. "Doctors have had the reins completely on deciding what is medically necessary and what is not, and that is increasingly going to have to come under scrutiny," says Colleen Flood, a law professor at the University of Toronto and a Canada Research Chair in Health Law and Policy. 'It's beholden on governments, who are spending public money, to take a look. ... The government obviously has to be involved in the sense that they set the budgets. Who else is going to represent the public interest if not them?'

Others who might be able to provide valuable input to the process include ethicists, scientists, public policy experts and philosophers, says Flood. Members of the public should also have a voice, though questions remain about how and when they should be involved.

"At what point, given the historical and political complexities inherent in medicare, could (and should) the public be involved?" Flood and colleagues have asked (www.law.utoronto.ca/sites /default/files/health_basket/docs/working 5_inandout.pdf). "What role could public values have in determining what services are publicly funded and which are left to the private sector?"

Whoever is involved, it is important that the process not merely be a bureaucratic exercise in saving money, says Flood. It must be a fair, reasonable process based on evidence. Most often, a decision regarding a particular test or procedure is not about whether it should be publicly funded - full stop - but rather about who really needs it and when is it necessary.

"We have to do this sort of thing to manage the health system," says Flood. "Individual doctors might not like having their decisions scrutinized, but why not? If you are making good decisions, why would you care?" Roger Collier, CMAJ

CMAJ 2012. DOI:10.1503/cmaj.109-4307

\section{Medically necessary: How to decide?}

I mplementing a process for making a decision based on defining a concept that may be indefinable can surprise, surprise - be rather complicated. Just ask those tasked with choosing which health services are "medically necessary." Yet, difficult as it may be, establishing a more explicit process for making that decision is viewed by many as a vital step in keeping Canada's health care system afloat.

And putting off the hard work required to establish such a process is probably a bad idea, considering that future advances in genetic medicine will only make the task more difficult, suggests Timothy Caulfield, a Canada Research Chair in Health Law and Policy at the University of Alberta in Edmonton.
"Being able to tailor therapies and treatments for individuals based on the personalized-medicine trend is going to complicate defining 'medically necessary' even more," says Caulfield.

Imagine, for instance, a physician informing Patient A that she is eligible for a particular therapy, then turning to Patient B, who has the same medical condition but isn't genetically predisposed to respond to the same treatment, and telling him that his provincial government will not cover the cost. This would likely go down as well as cod liver ice cream.

"It could in some ways be more precise, but it could become even messier," says Caulfield.

Of course, reluctance on the part of some health professionals to define cer- tain terms - "minimal," "adequate" and "required," to cite but a few ambiguous examples - should come as little surprise considering the many unsuccessful efforts to do so in the past. As for putting great effort into coming up with a tidy, all-encompassing definition of "medically necessary" — it's probably a waste of time, Caulfield has suggested (Health Law J 1996;4:63-85).

"There are those who believe a definition of this term, usually in the form of a list of services or as a basic benefits package, will provide a solution to certain health policy concerns. Both federal and provincial should resist pressure to adopt this approach," wrote Caulfield. "Given the history of the concept of 'medically necessary' and 